\title{
HYDROLOGY MODELS APPLICATION TO SOLUTION OF THE RIVER DEVIATION PROBLEM DURING DAM CONSTRUCTION
}

\author{
Olga Nitcheva $^{1 *}$, Polya Dobreva ${ }^{1}$, Borislav Milev $^{2}$, \\ EMIL BOURNASKI ${ }^{3}$ \\ ${ }^{1}$ Institute of Mechanics, Bulgarian Academy of Sciences, \\ 4, Acad. G. Bonchev Str. BG-1113 Sofia, Bulgaria \\ ${ }^{2}$ Ss Cyril and Methodious European Politechnical University, \\ 23 Str., Pernik, Bulgaria \\ ${ }^{3}$ Institute for Climate, Atmosphere and Water Research, \\ Bulgarian Academy of Sciences, 66 Tsarigradsko Shose Blvd, Sofia, Bulgaria \\ [Received: 1 February 2019. Accepted: 13 May 2019] \\ doi: 10.7546/JTAM.49.19.02.08
}

\begin{abstract}
Building of dams on mountainous rivers in narrow valleys always gives rise to the problem of the river waters deviation during the construction period. It becomes especially important in the periods of flood waves (FW) threatening with floods bringing considerable losses to the builders. Mostly the problem is solved by river deviation structures consisted of a weir, barring the river dam upstream and forming a small lake, a deviation tunnel or canal and sometimes a downstream weir. They have to transfer the river discharge from the upstream to the downstream side rounding the construction area. $Q_{\max p}$ is the river discharge with assumed exceedance probability $p$, which is expected to minimise the sum of the losses caused by the flood as well as the cost of the deviation structures.

As the problem looks serious enough the evaluation of the $\mathrm{Q}_{\max p}$ at the dam site with absence of the river flow observations must be done by larger number of methods. The article suggests the job to be performed through employment of more or less sophisticated hydrology models with or without consideration of the weir impounded lake's FW retention. For limited up to $2000 \mathrm{~km}^{2}$ catchments a simple partly based on empirical formulae model is proposed.
\end{abstract}

KEY WORDS: Dam building, river waters deviation, hydrology models employment

\section{INTRODUCTION}

As a rule, the dams are river valleys. Difficult stage in their performance is the excavation of the foundation and building of their lower, near the base parts. It is

\footnotetext{
${ }^{*}$ Corresponding author e-mail: olgani @imbm.bas.bg
} 
a problem because of the need for diversion of the river flow from its bed in a way not to hinder the dam building. Considering the possibility of multiple increase of the river discharge during the year and the formation of flood waves (FW), it is clear that the diversion of the river during the dam building is a demanding task and its' not good enough solution can cost a lot for the builder. Flooding the foundation pit and the partly constructed dam entails not only unforeseen costs for removing its effects, but also a delay of the construction. That's why the scheme for defence of the construction pit from the river water is an essential part of the dam design project.

During building of dams located in the lower part of large rivers, such as Danube for example, the water elimination from the excavated area is carried out through various ways of partial fencing, similar to bridge building. Such conditions for dam construction are not typical for Bulgaria.

During the greater part of the year the water flow in the rivers in the higher and middle parts of their course is insignificant. That is why for dam construction in mountainous areas the best way for the river diversion is employment of bypass tunnels or channels. For the purpose in front of the dam excavation pit the river gets barred by a barrage which often represents a solid concrete or embankment dam. In front of this weir situated is the tunnel entrance opening. These structures must be dimensioned in a way to divert during dam construction the low and high waters as well.

The amount of the maximum annual water discharge $\left(Q_{\max }\right)$ or the volume of the flood wave $(\mathrm{FW})$ depends on the return period. It can be expressed also by the probability of exceedance $P \%$. For example the water discharge having return period (T) of 1,000 years (it happens in average once per 1,000 years), has $P=0.1 \%$, or $T=1 / P \%$. $Q_{\max }$ or FW with such $P \%$ should be determined by theoretical assessments, because there are no observations during such long periods.

The choice of the $Q_{\max }$ return period for the diversion structures dimensioning should be made by economical assessments. The greater the return period, the greater $Q_{\max }$, and the bigger and expensive is the diversion barrage and tunnel. In the same time the smaller will be the probability for the building site flooding and lesser damage consequences. However such assessments are difficult and have a probabilistic nature.

Depending on the retention capacity of the storage created by the barrage, the floodwaters should be assessed either as maximum water discharges or as flood waves. The flood wave except for the peak $Q_{\text {peak }}=Q_{\max }$ has a volume. The significant for the deviation structure dimensioning is the part with rising discharge up to the peak $-Q_{\max }$, that's true in the both cases - with or without retention lake upstream the barrage. 
Usually the FW are presented as a triangle with a peak $\left(Q_{\text {peak }}\right)$ and base equal to the duration of the FW. When the maximum stored water volume by the diversion dam is significant compared to the $\mathrm{FW}$ volume, part of it is retained and the maximum Q passing through diversion tunnel is less than $Q_{\text {peak }}$. In that case it is important to be determined not only $Q_{\text {peak }}$, but also the FW volume and shape. When the retention capacity of the barrage storage volume is small, the retention effect is negligible and then it is sufficient determination of $Q_{\max }$ only.

The height of the diversion weir and the diameter of the tunnel depend on $Q_{\max }$ or FW volume, shape and peak $\left(Q_{\text {peak }}\right)$ and the retention capacity of the lake formed in front of the diversion barrage. In the second case, the smaller is the FW volume, the smaller are the dimensions of the diversion structures. Therefore essential for their effectiveness is the accuracy of determining the flood wave parameters with the assumed return period.

\section{Methods for Determination of the High WaVe Parameters}

The most accurate assessment of these parameters is based on data from hourly or at least half-daily measured water discharges at gauge stations (GS). Often there are no such stations near the dam. There are hydrological methods for their assessment based on observations in other GS in the same watershed or similar catchments, but their application requires a lot of data processed by statistical and probability methods [1-3].

A simple model, for calculation of $Q_{\max }$ caused by rain with desired return period at a point with small watersheds in absence of measurements, is given in the "Methodology for assessment of the maximal runoff", developed in the National Institute of Meteorology and Hydrology by Strahil Gerasimov. It is accepted as national methodology in 1987 by the Committee of Environment (the predecessor of the Ministry of Environment and Water) [4] and is in force for high waves from small and middle size catchment since then. The method is based on the availability of evaluated for different regions of Bulgaria mean maximal round o'clock precipitation. Also for each country region evaluated are conversion coefficients for calculation of the maximum 24 hours precipitation with extremely small probability of exceedance as $0.01 \%, 0.1 \%, 1 \%, 5 \%, 10 \%, 20 \%$ and $50 \%$ on the basis of the mean values. The method gives the possibility for calculation of the $Q_{\text {peak }}$ and FW shape and volume using different coefficients, accounting for the size, length, slope and other characteristics of the watershed.

The method is considered as applicable for catchments area up to $2000 \mathrm{~km}^{2}$, which for a mountainous country as Bulgaria is rather suitable. Most of the big reservoirs in the country have smaller watersheds. 
The method created by the Russian scientist Alexeev and further developed by Prof. Strahil Gerasimov from NIMH [4] is based on a very simplified mechanistic model. It assumes that after the start the precipitation continues uniformly distributed over the whole catchment area with the same rate until the flow formed at the most remote point of the watershed reaches the point of measurement. That time interval is called concentration time (CT) and it is considered as the period of rise of the FW with the discharge reaching the peak $Q_{\text {peak }}$. The flow velocity is calculated by two types of empirical formulae, for more or less steep riverbeds. The main factors in them are the water maximal discharge at the arrival point, the mean flow route inclination and the coefficient of roughness. The last one should be assumed according to the type of the flow route helped by the tables given in the methodology.

An important feature of the latter is the assumption of the rain intensity during the CT. There given are in tables the intensities corresponding to the CT as part of the round o'clock rain with the assumed return period typical for the different regions in Bulgaria. The shorter is the CT the higher is the intensity. This way the method brings to highest possible values of the expected $Q_{\text {peak }}$ from the assumed 24 hours duration rain.

The next key point of the method with a very important role for obtaining more realistic results is the assumption of the runoff coefficient. It should be selected from a number of tables, specifying the characteristics of the watershed rain retaining and infiltration properties $[5,6]$. It depends on the watershed size and the rain intensity.

The method gives also the shape and the volume of the FW assumed as a triangle which rising limb height is equal to the $Q_{\text {peak }}$ and the base - to the concentration time. The descending limb is equal to the time of recession, mostly accepted as equal to 2-2.5 times the length of the rising limb.

The main advantage of the method beside its simplicity is the small possibility of making big mistakes because it is always possible a rough estimation outlining the possible higher and lower limits of the estimated FW [7].

The applicability of the method has been investigated for assessment of the flood discharges at a point with gauge station No 23250 on the Vidima river, tributary of Rossitza river (Fig. 1), close to the town of Sevlievo. There were registered the 24 hours rain and the resulting discharges during many years period in the end of the last century. The model obtained parameters, after some adjustment of the runoff coefficient, were matched to the measured ones. Such experimental studies were performed for several flood wave events with exceedance probability 50\% and higher. The study proved undisputed validity of the model. It also showed the increase of the runoff coefficient with 10 and more percent when the flood event follows small rains in the preceding day wetting the soil surface layer [8].

Other more precise method for evaluation of maximum water discharges at points 
194 Hydrology Models Application to Solution of the River Deviation Problem ...

with catchments of different size is the use of distributed hydrological rain-runoff models. Such models determine the runoff in quantity and time, taking into account topography, soil and climate conditions and vegetation cover of the catchment $[9,10]$. All those data are input and the result is the daily, monthly or yearly runoff at a selected point and time periods. The runoff estimated by these models with prescribed precipitation will logically be better evaluated than the simplified method of NIMH with the same precipitation. The usage of such models is far more complex work, needing huge amount of data. It is justified when large watersheds are regarded with available data. Even then the problem involves great amount of uncertainty concerning the realism of the assumed rain layer, the possibility of its uniform territorial distribution for many hours on a vast area and the probabilistic evaluation of the event.

Instead of using prescribed precipitation the FW could be modelled, based on natural rain events with assessed return periods, and later the result be approximately converted to the required exceedance probability. It is more than obvious the described above calculations and their interpretation will be rather intricate job.

\section{Case Study application of the Str. Gerasimov Method to THE “Al. Stambolitski” DAm CATChMENT}

As at the moment in Bulgaria there aren't dams in design stage, expecting solution of the FW deviation problem, for practical demonstration of the methodology the site of "Alexander Stamboliiski" dam was selected. The main reason for the choice is the presence of a hydrometer station in the middle of the reservoir catchment, which can help in the assessment of the model results realism.

It is the highest reservoir in the Yantra watershed erected in 1953 on the Rossitza river. The dam is made of stone masonry with height at the middle section equal to $66 \mathrm{~m}$. The maximal water surface elevation is equal $190 \mathrm{~m}$. The area of the catchment (Fig. 1) equals to $1478 \mathrm{~km}^{2}$, which makes it suitable case for the methodology application [11].

The other necesssary data are as shown bellow. The distance from the remotest point of the catchment to the dam site is equal of $94 \mathrm{~km}$. The mean inclination is estimated as close to $6 \%$. The flow bed roughness eoefficient is assumed as 0.05 . In the catchment upstream the dam site there aren't reservoirs possible to retain the runoff.

The mean elevation of the watershed, excluding the initial short and steep several killometres high mountain part, equals approximately to $800 \mathrm{~m}$. For that elevation and the geographic region of the reservoir the tables of the method show the mean annual maximum round o'clock pressipitation as equal to around $50 \mathrm{~mm}$. The conversion coefficient (the quantal) corresponding to $20 \%$ exceedance probability of the 24 hours 


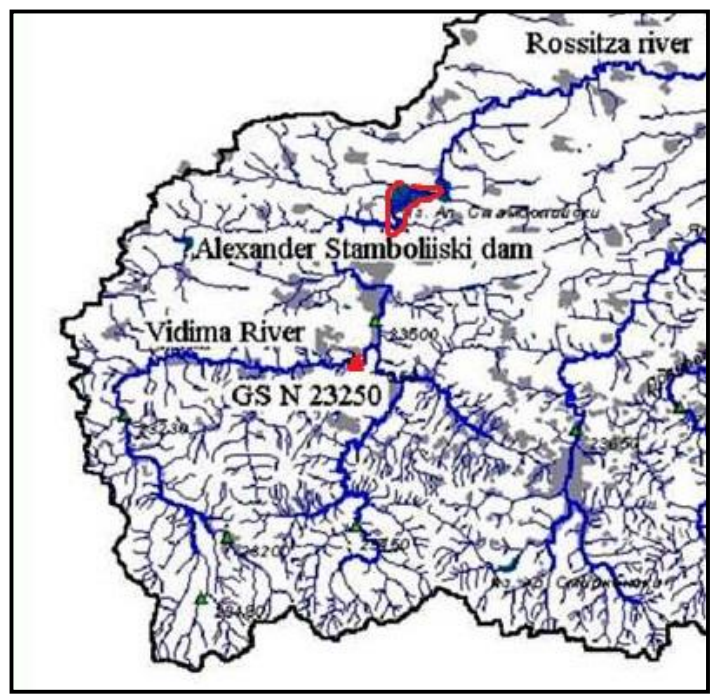

Fig. 1. (Color online) Map of "Al. Stamboliiski” catchment.

rain is equal to 1.29. The value of the runoff coefficient for the type of the soil and the catchment cover and size, considering the rain exceedance probability, could be assumed equal to 0.38 .

The calculation by the method yields the following figures: the peak of the FW $Q_{\max 20 \%}=520 \mathrm{~m}^{3} / \mathrm{s}$, mean velocity of the water flow when reaching the peak discharge at the dam site $V=1.30 \mathrm{~m} / \mathrm{s}$ and time of concentration $20.1 \mathrm{~h}$. The FW volume with triangular for simplicity presentation of the $\mathrm{FW}$ hydrograph with height $520 \mathrm{~m}^{3} / \mathrm{s}$ and basis equal to three times of the concentration time, i.e. $60.3 \times 3600 \mathrm{~s}$ is equal to $56 \times 10^{6} \mathrm{~m}^{3}$.

These figures look very high but the comparison to the FW peak, measured in 24.09.1964 at the gauge station (GS) No 23250 (Fig. 1) after 24 hours rain of $46.6 \mathrm{~mm}$ with exceedance probability greater than $50 \%$ is equal to $424 \mathrm{~m}^{3} / \mathrm{s}$. The catchment of the GS equals to $560 \mathrm{~km}^{2}$ (close to 3 times smaller than the area of the "Al. Stambolijski" catchment) the length of the flow route is $61 \mathrm{~km}$, the CT $=14 \mathrm{~h}$, the FW volume is equal to $26.8 \times 10^{6} \mathrm{~m}^{3}$. The comparison is a convincing evidence about the realism of the obtained by Gerasimov's methodology $Q_{\max } 20 \%$ at the regarded dam site.

As the layout in Fig. 2 shows in front of the construction pit of the dam, there much likely must have been space enough for formation of a significant lake capable for essential retention of the flood wave, resulting in considerable reduction of the flowing into the deviation tunnel maximal discharge. 


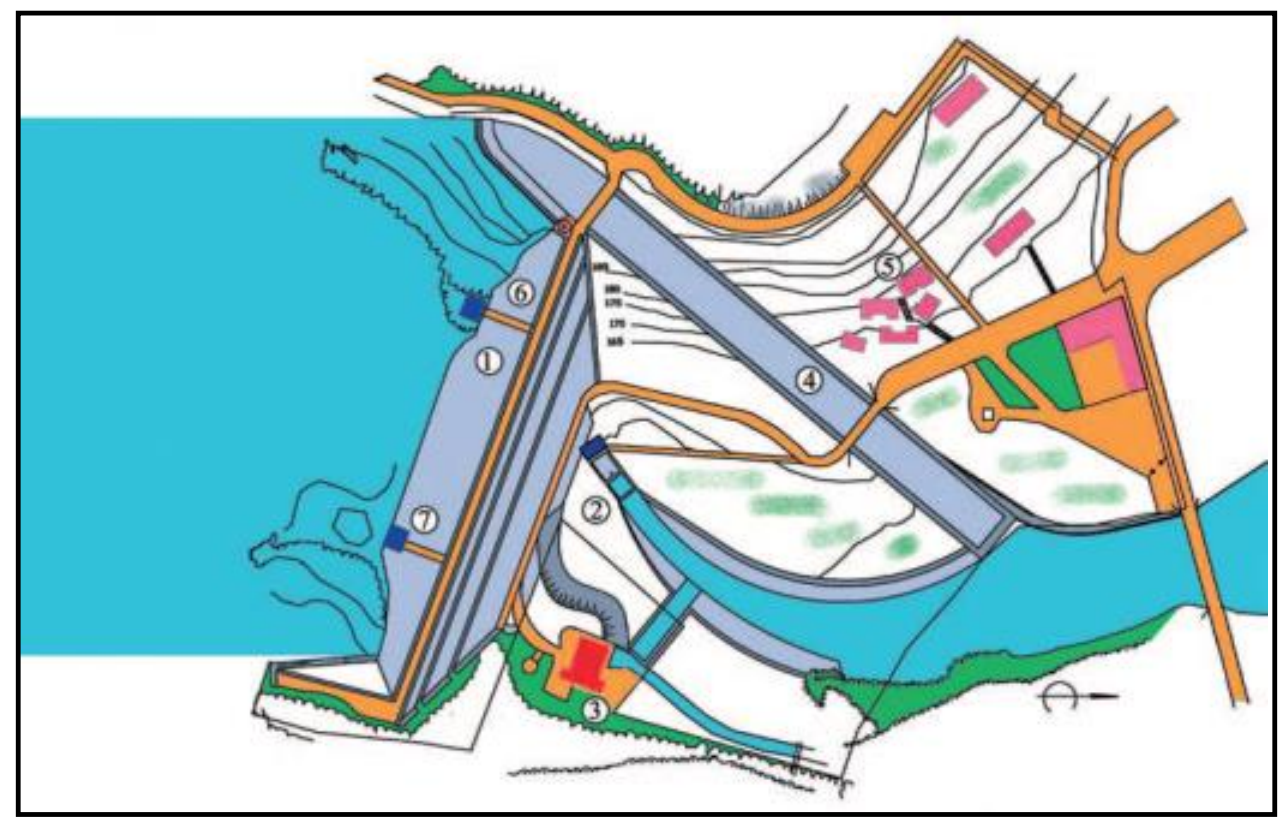

Fig. 2. (Color online) Layout of "Al. Stamboliiski" dam (1 Dam body; 2. Bottom outlet; 3. Power plant; 4. Spillway; 5.Residential houses; 6. Bottom outlet entrance tower; 7 Power plant intake tower).

\section{Diversion Structures Dimensioning}

\section{CALCULATION OF THE DIVERSION BARRAGE HEIGHT}

The elevation of the diversion barrage crest will be obtained by adding a certain reserve, for example equal of $0.5 \mathrm{~m}$, above the elevation of the water level, necessary the maximum discharge $Q_{\max }$, reached in result of the FW retention, to flow into the tunnel.

The process of the flood wave inflow into the lake, formed by the barrage, and its transfer through the tunnel is illustrated in Fig. 3, it is so-called solitary wave [12-14]. At the beginning the river flow $Q_{p}=Q_{o}$. The damming by the barrage creates the head $H_{o}$ enough for diversion of $Q_{o}$ into the tunnel and flowing down with a depth $h_{1}$. at the beginning [15]. With the progress of flooding the river flow $Q_{p}$ increases. This brings to the rise of the lake level and $H_{o}$ as well. As a result the water diverted into the tunnel is $Q_{o}<Q_{p}$ and it flows with increasing depth $h_{1}$. This process continues until reaching the equality $Q_{o, \max }=Q_{p}$, which takes place after the FW hydrograph has passed the peak max $Q_{p}$. From this moment, of $Q_{o}>Q_{p}$, and the water level in the retention lake drops down, until the discharge in the river reaches the normal 
level $Q_{p}$. In this evaluation procedure we are interested in the value of $Q_{o, \max }$.

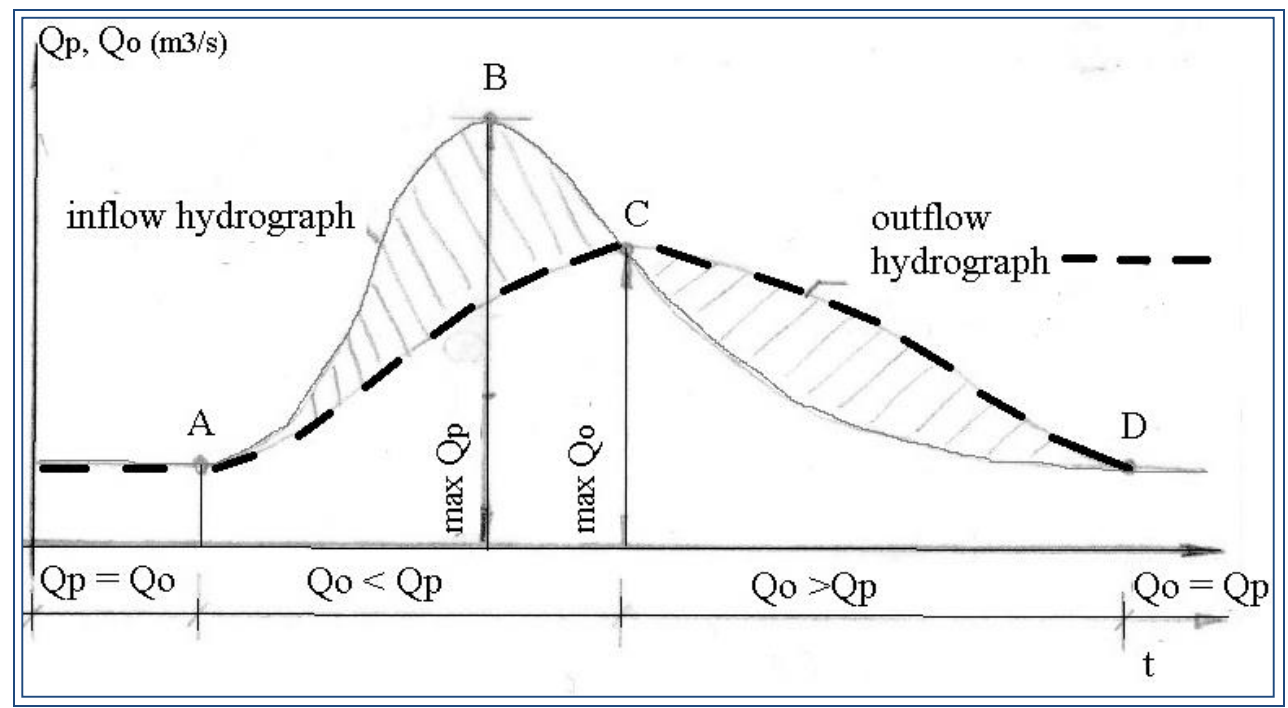

Fig. 3. Flood hydrograph $Q_{p}=F(t)$ of the river flow and drainage in the tunnel $Q_{o}$.

To determine $Q_{o, \max }$ the flood wave retention should be calculated. It is described by the balance equation between the flow volumes into the lake and deviated though the tunnel and the change of the lake volume

$$
\left(Q_{p}(t)-Q_{o}(t)\right) d t=d V
$$

where $V$ is the volume of the lake in front of the barrage.

$Q_{o}(t)$ depends on the difference between the water level before the tunnel entrance and the water level at the beginning of the tunnel (Fig. 4). To determine the last water level it is necessary to be known the depth of the water flow $h_{1}$ at the beginning of the tunnel. For calculation procedure it is necessary to have the dependency $h_{1}=f\left(Q_{o}\right)$, built in the process of the tunnel hydraulic dimensioning. The calculation of the retention by that differential equation is done in finite differences through successive time steps $\Delta t$. For the time step $n$ it will look as follows:

$$
\left(Q_{, n}-Q_{o, n-1}\right) \Delta t=\Delta V_{n}
$$

with $t_{n}=t_{n-1}+\Delta t, V_{n}=V_{n-1}+\Delta V_{n}$.

At the initial moment $n=0$ we have $t_{0}=0, Q_{, 0}=Q(0), Q_{o, 0}=Q_{, 0}$ (water discharge in the tunnel in low water conditions) and $V_{0} \approx 0$. 


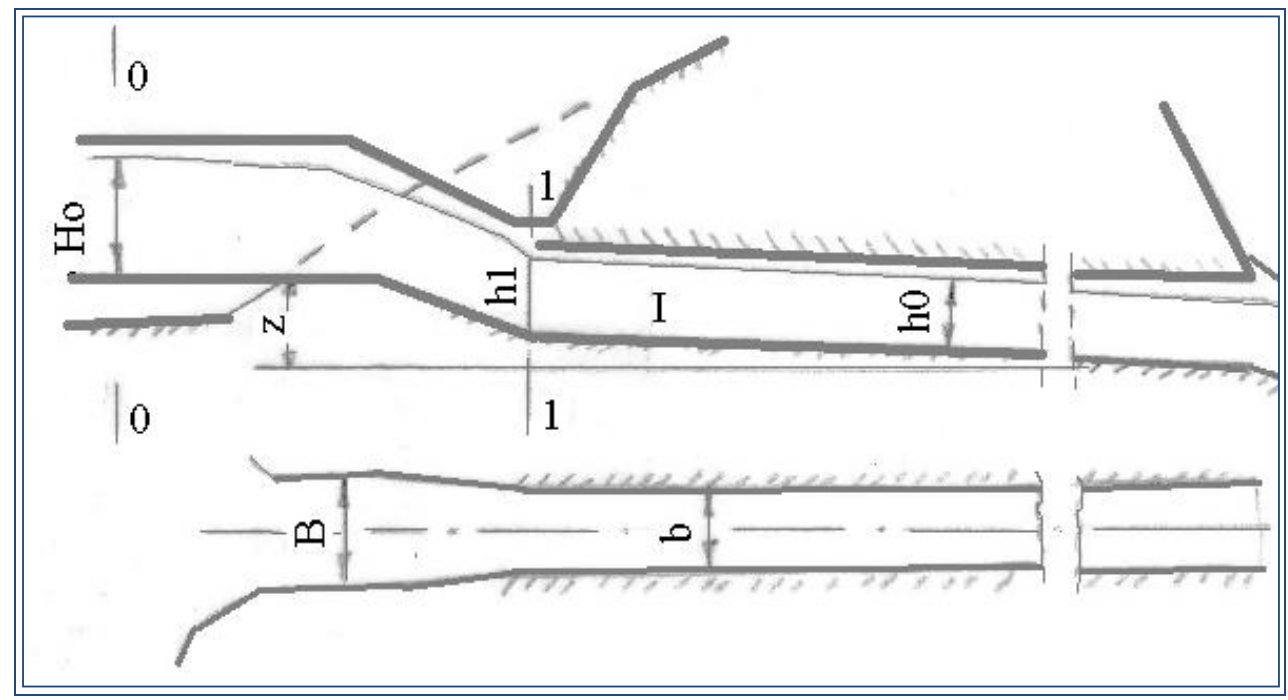

Fig. 4. Longitudinal section and horizontal plan of a diversion structure.

$Q_{, n}$ can be calculated from the inflow hydrograph equation $-Q(t)=f(t)$ at the moment $t_{n} . Q_{o, n-1}$ is the discharge flowing through the tunnel at the end of the time step $n-1$, when the water head in front of the tunnel is $H_{o, n-1} \cdot Q_{o, n-1}$ is derived from Bernoulli equation (equality of the sum of the potential and kinetic energy of the water flow in the sections before and after the tunnel entrance. According to Fig. 4 the equality of energies in sections $0-0$ and $1-1$ can be written as

$$
{ }_{, n}+Z=h_{1, n-1}+\left(v_{n}^{2} / 2 g\right) \varphi^{2} .
$$

$h_{1, n-1}$ is the depth of the flow at the entrance of the tunnel at the end of the preceding interval. $v_{n}$ is the speed in the tunnel $-v_{n}=Q_{, n} / F$, as $F=b h_{1, n}$, and $Z$ is the difference between the level of the threshold and the tunnel bottom at the exit. $\varphi$ is the velocity coefficient, accounting for the hydraulic losses at the tunnel entrance and can be assumed equal to 0.9 .

If $h_{1, n-1}$ is known from equation (2) for each, $Q_{, n}=F v$ could be determined.

The algorithm of the solution is as follows. The first step is $n=1$, the equation (1) has the form $\left(Q_{, 1}-Q_{, 0}\right) . \Delta t=\Delta V_{1} \rightarrow V_{1}=0+\Delta V_{1}$. The volume-elevation relation curve gives for $V_{1}$ the water surface elevation in front of the tunnel entrance. The head $H_{o, 1}$ in front of the tunnel is the difference between that elevation and the same of the threshold. For that head by formula (2) for $h_{1,0}$ calculated is the tunnel inflow discharge $Q_{0,1}$. The dependence $h_{1}=f\left(Q_{0}\right)$ defines $h_{1}=h_{1,1}$. The calculation is repeated for the second step $\left(Q_{, 2}-Q_{, 1}\right) . \Delta t=\Delta V_{2} \rightarrow V_{2}=$ 
$V_{1}+\Delta V_{2} \rightarrow$ new value for the head ${ }_{0,2}$ and $Q_{0,2}$ for $h_{1}=h_{1,1}$, etc.

Thus, in equation (1) for each step all is known except for $\Delta V_{n}$. After its determination $H_{o, n}$ is calculated and from equation (2) $Q_{o, n}$ is defined. The latter makes possible the determination of $h_{1, n}$. The solution is in explicit scheme - in (1) for $Q_{o}$ and in (2) for $h_{1}$ assumed are their values at the end of the preceding step $n-1$, instead of the values in the current step $n$. $\Delta t$ must be small enough for stable solution, which means to calculate smooth increments of $Q_{o}$ at every time step. Normally it is assumed $\Delta t$ equal of 1 hour. The calculation proceeds until $Q_{o, \max }$, respectively $o, \max$ are reached. The calculation could be repeated with smaller or greater tunnel cross section dimensions for obtaining more acceptable height of the weir and accordingly smaller total value of the diversion structures.

The relation $h_{1}=f\left(Q_{o}\right)$ is obtained by hydraulic calculation of the tunnel. It is a routine hydraulic calculation used in the hydraulic structures design practice which description in the article is not relevant.

\section{CONCLUSIONS}

The precise dimensioning of the structures for evacuation of the river water during dams building is important for their economical and safe construction. The developed methods and models for determination of the maximum water discharges and flood waves shape and volume, make possible more reliable assessment of their size and return period. Modern computing tools allow carrying out laborious and complex calculations like accounting for the flood wave retention effects and iterative calculations of the necessary height of the barrage and diameter of the tunnel. The report describes methods for their implementation.

\section{ACKNOWLEDGEMENT}

This work has been carried out in the framework of the National Science Program "Environmental Protection and Reduction of Risks of Adverse Events and Natural Disasters", approved by the Resolution of the Council of Ministers No 577/17.08.2018 and supported by the Ministry of Education and Science (MES) of Bulgaria (Agreement No DO1-230/06-12-2018).

\section{REFERENCES}

[1] N. HRistova (2007) Flood Waves Parameters For High Mountains Watersheds. Annual of Sofia University "St. Kl. Oxridski" 99(2) 71-86.

[2] N. HRistova (2012) "Bulgarian River Waters". Sofia, ISBN: 978-954-723-080-4.

[3] N. Hristova, E. Ivanova, U. Seimenov (2017) Geographical Aspects of Floods in Northwest Bulgaria. KNOWLEDGE - International Journal Scientific and Applicative Papers 16(2) 907-914. 
[4] S. Gerasimov (1988) "Methodology for Determination of the Maximum Runoff of the Bulgarian Rivers". MOSW Sofia.

[5] E. Tcvetkova, S. Rousseva, T. Mitova, V. Koutev (2009) Soil Erosion, Carbon and Nutrient Element Leaching Control by Reduced Tillage on Chromic Luvisol. In: Proceedings of the International Conference Soil Tillage and Ecology, 1-5 September, pp. 117-121.

[6] N. Zhivkova, V. Koutev, E. Zlatareva (2011) Spatial Distribution of Soluble Salts in Southeast Bulgaria - Kermen Soil Monitoring Site. In: 14. Gumpensteiner Lysimetertagung. Lysimeters in Climate change Research and Water Resources Management. 3-4 May, Gumpenstein, Austria; ISBN: 978-3-902559-61-6, p. 195-198.

[7] A. Yordanova, I. Ilcheva (2013) Determination of Flood Hydrograph for Bebresh Reservoir. Science and Technology Journal 4 36-40.

[8] O. Santourdjian, V. Ioncheva (2016) Determination of the Rain-Runoff Relation for Flood Risk Real Time Management Purposes. Parts 1 and 2. Water Affairs Magazine (1/2) 2-8 and (3/4) 34-40.

[9] O. Nitcheva, B. Milev, L. Hrischev (2016) Management of Natural Hazards. Water Affairs Magazine (1/2) 9-13.

[10] O. NitcheVA (2018) Hydrology Models Approach to Estimation of the Groundwater Recharge. Case Study in the Bulgarian Danube Watershed. Environmental Earth Sciences 77464.

[11] T. Trenkova (2018) Rule Curves for Appropriate Management of Al. Stamboliiski Reservoar. Water Affairs Magazine (5/6) 25-32.

[12] E. Nikolova (2019) Evolution Equation for Propagation of Blood Pressure Waves in an Artery with an Aneurysm. Studies in Computational Intelligence 793 Springer, Cham 327-339.

[13] E. Nikolova, I. Jordanov, Z. Dimitrova, N. Vitanov (2018) Nonlinear Evolution Equation for Propagation of Waves in an artery with an Aneurysm: An Exact Solution Obtained by the Modified Method of Simplest Equation. Advanced Computing in Industrial Mathematics Studies in Computational Intelligence 728 Springer, Cham 131-133.

[14] N. Vitanov, Z. Dimitrova, H. Kantz (2010) Modified Method of Simplest Equation and Its Application to Nonlinear PDEs. Applied Mathematics and Computation 216 2587-2595.

[15] I. PATOKOV (1986) "Hydraulic Structures". Technika. 